\title{
Zestawienie publikacji i ważniejszych osiągnięć Katedry Dydaktyki Języka i Literatury Polskiej
}

\section{Publikacje książkowe (monografie autorskie i zbiorowe)}

\section{Wydane do roku 1999}

Mikuta M.: Kultura żywego stowa. Warszawa 1961.

Cofalik J., Tabakowska I.: Ksztaltowanie języka ucznia w procesie nauczania języka polskiego. Warszawa 1963.

Polański E.: Badania nad ortografia uczniów. Katowice 1969.

Co falik J.: Ćwiczenia precyzji językowej uczniów. Warszawa 1979.

Polański E.: Stownictwo uczniów. Problemy, badania, wnioski. Warszawa 1982. Synowiec H.: Rozwój słownictwa nazywającego cechy osobowości w języku dzieci i młodzieży. Katowice 1985.

Polański E.: Dydaktyka ortografii i interpunkcji. Wyd. 1. Warszawa 1987.

Niesporek-Szamburska B.: Język wierszy dla dzieci (na materiale „Świerszczyka"). Katowice 1990.

Synowiec H.: Sprawność językowa uczniów w ślaskim środowisku gwarowym. Problemy, badania, konsekwencje dydaktyczne. Katowice 1992.

Jaskółowa E., Opacka A.: Prady i konwencje w poezji. Kraków 1995.

Jaskółowa E., Opacka A.: Prady i konwencje w prozie. Kraków 1995.

Polański E.: Dydaktyka ortografii i interpunkcji. Wydanie drugie zmienione. Warszawa 1995.

Ogłoza E., Polański E., Szymik E.: Drama na lekcjach języka polskiego w klasach IV-VIII. Kielce 1996.

Jaskółow a E.: Od poezji kosmosu do poezji czasu. Studium o twórczości Stanistawa Ciesielczuka. Katowice 1997. 
Opacka A.: Trwanie i zmienność. Romantyczne ślady oralności. Katowice 1998.

\section{9}

Synowiec H.: Śląkie czasopisma szkolne (1922-1939). Katowice 1999.

\section{0}

Interpretacje i szkota. Red. A. Opacka. Katowice 2000.

W kręgu języka i kultury ziemi pszczyńskiej. Red. M. Siuciak, H. Synowiec. Katowice-Suszec 2000.

Z problematyki ksztatcenia językowego, literackiego i kulturowego. Materiaty pomocnicze dla uczniów i studentów filologii polskiej. Red. A. Grochulska, E. Polański. Piotrków Trybunalski 2000.

\section{1}

Bochenek K., Polański E., Szczepocka-Walas A.: 10. jubileuszowe „Dyktando" ogólnopolskie, historia, wywiady i teksty. Łódź 2001.

Jaskółowa E.: Literatura polska. Od „Bogurodzicy” do poezji Szymborskiej. Chicago-Warszawa 2001.

\section{2}

Interpretacje i reforma. Red. A. Opacka. Katowice 2002.

$W$ kręgu zagadnień dydaktyki języka i literatury polskiej. Księga jubileuszowa dedykowana Profesorowi Edwardowi Polańskiemu. Red. H. Synowiec. Katowice 2002.

\section{4}

Bula D., Krzyżyk D., Niesporek-Szamburska B., Synowiec H.: Dziecko w świecie języka. Kraków 2004.

Krzyżyk D., Synowiec H., Zarzycki G.: Chorzowskie spotkania z „Ślaska Ojczyzna Polszczyzna”. Edukacja regionalna - gwara - sztuka recytacji. Chorzów 2004.

Niesporek-Szamburska B.: Językowy obraz pór roku i tradycji kulturowych w twórczości dzieci. Katowice 2004.

Przybyla O.: Akty mowy w języku nauczycieli. Katowice 2004.

„Z Teorii i Praktyki Dydaktycznej Języka Polskiego”. T. 17. Red. H. Synowiec. Katowice 2004.

\section{5}

„Z Teorii i Praktyki Dydaktycznej Języka Polskiego”. T. 18. Red. H. Synowiec. Katowice 2005. 


\section{6}

Jaskóła E.: I kto to byt? Żona Lota w poezji polskiej, czyli rozbijanie stereotypu. Katowice 2006.

Koziołek K.: Czytanie z innym. Etyka. Lektura. Dydaktyka. Katowice 2006.

Polański E.: Ortografia i interpunkcja $w$ zintegrowanym ksztatceniu wczesnoszkolnym. Mysłowice 2006.

Polański E., Rychlik A.: Ortografia i interpunkcja w szkole. Praktyczne kompendium nie tylko dla nauczycieli (szkoła podstawowa, gimnazjum, liceum). Łódź 2006.

\section{7}

Krzyżyk D., Leś W., Synowiec H.: Spotkanie z gwara i kultura regionu. Konkurs recytatorski w gwarze śląskiej - Śląska Ojczyzna Polszczyzna. Mysłowice 2007.

Na marginesach dyskursu. Red. M. Jaworska, M. Strużek. Katowice 2007. Podręczniki do kształcenia polonistycznego w zreformowanej szkole — koncepcje, funkcje, język. Red. H. Synowiec. Kraków 2007.

Wójcik-Dudek M.: (Prze)trwać w okolicach mitu. O funkcjach mityzacji w poezji Tadeusza Nowaka. Katowice 2007.

\section{8}

Kołodziej A., Niesporek-Szamburska B.: Tworzyć teksty. Kielce 2008.

Krzyżyk D.: Synonimia pojęć prawdziwościowych - teoria i nauczanie. Katowice 2008.

\section{9}

Kołodziej A., Niesporek-Szamburska B.: Konteksty i uwarunkowania zadań domowych. Kielce 2009.

\section{0}

Dziecko - język - tekst. Red. B. Niesporek-Szamburska, M. Wójcik-Dudek. Katowice 2010.

Gąsiorek K., Krzyżyk D., Synowiec H.: Funkcje i struktura oraz język podręczników do kształcenia zawodowego. Przewodnik dla autorów $i$ wydawców. Warszawa 2010.

Kołodziej A., Niesporek-Szamburska B.: O dialogu kultur w edukacji polonistycznej (na poziomie szkoły podstawowej). Kielce 2010. 


\section{2}

Krzyżyk D., Synowiec H.: Kryteria oceny podręcznika szkolnego w aspekcie językowym. Przewodnik dla rzeczoznawców wraz ze wzorami opinii. Warszawa 2012 (współautorki: K. Gąsiorek, A. Hącia, K. Kłosińska, J. Nocoń) [dostęp: http://www.men.gov.pl].

Praca z uczniem o specjalnych potrzebach edukacyjnych. T. 1. Red. A. Guzy, D. Krzyżyk. Kielce 2012.

Wiedza o języku i kompetencje językowe uczniów. Red. B. Niesporek-Szamburska. Katowice 2012.

Zaczytani. Red. M. Bernacki, T. Bielak, I. Gielata, K. Koziołek. Bielsko-Biała 2012.

\section{3}

Niesporek-Szamburska B.: Stereotyp „czarownicy” i jego modyfikowanie. Na przykładzie tekstów dla dzieci i wypowiedzi dziecięcych. Katowice 2013. Nowe odstony klasyki w szkole. Literatura XIX wieku. Red. E. Jaskóła, K. Jędrych. Katowice 2013.

Nowe opisanie świata. Literatura i sztuka dla dzieci i młodzieży w kręgach oddziatywań. Red. B. Niesporek-Szamburska, M. Wójcik-Dudek. Katowice 2013.

Odmiany polszczyzny w szkole. Teoria i praktyka. Red. H. Synowiec, przy współudziale M. Kubarek. Katowice 2013.

Praca z uczniem o specjalnych potrzebach edukacyjnych. T. 2. Red. A. Guzy, B. Niesporek-Szamburska. Kielce 2013.

Synowiec H.: Ślaska ojczyzna polszczyzna z perspektywy edukacyjnej. Katowice 2013.

\section{4}

Językowe, literackie i kulturowe ścieżki edukacji polonistycznej (tradycja i wspótczesność). Red. D. Krzyżyk, B. Niesporek-Szamburska. Katowice 2014.

„Logopedia Silesiana”. T. 3. Red. O. Przybyla. Katowice 2014.

Ochwat M.: Poezja paradoksów, paradoksy w poezji. Poetycka teologia Jana Twardowskiego, Janusza Pasierba, Wactawa Oszajcy. Katowice 2014.

Ogłoza E.: Wokót opowieści Hansa Christiana Andersena. O radości czytania. Katowice 2014.

Wyczytać świat - międzykulturowość $w$ literaturze dla dzieci i młodzieży. Red. B. Niesporek-Szamburska, M. Wójcik-Dudek przy współpracy A. Zok-Smoły. Katowice 2014. 
„Z Teorii i Praktyki Dydaktycznej Języka Polskiego”. T. 23. Red. H. Synowiec. Katowice 2014.

\section{5}

Guzy A., Jagodzińska D., Wacławek M., Zok-Smoła A.: Czas na... Język $i$ dydaktyka w badaniach młodych naukowców. Katowice 2015.

Fundamenty czy fundamentalizmy. Antyk grecko-rzymski i Biblia w szkole. Red. E. Jaskółowa, K. Biedrzycki. Warszawa 2015.

(Przed)szkolne spotkania zlektura. Red. B. Niesporek-Szamburska, M. Wójcik-Dudek przy współpracy A. Zok-Smoły. Katowice 2015.

Szkoła bez barier. O trudnościach w nauczaniu i uczeniu się. Red. A. Guzy, B. Niesporek-Szamburska, M. Wójcik-Dudek. Katowice 2015.

„Z Teorii i Praktyki Dydaktycznej Języka Polskiego”. T. 24. Red. D. Krzyżyk. Katowice 2015.

\section{6}

Edukacja polonistyczna jako zobowiąanie. Powszechność i elitarność polonistyki. T. 1. Red. E. Jaskółowa, D. Krzyżyk, M. Wójcik-Dudek, B. Niesporek-Szamburska przy współpracy D. Jagodzińskiej i A. Zok-Smoły. Katowice 2016.

Edukacja polonistyczna jako zobowiązanie. Powszechność i elitarność polonistyki. T. 2. Red. E. Jaskółowa, D. Krzyżyk, M. Wójcik-Dudek, B. Niesporek-Szamburska przy współpracy D. Jagodzińskiej i A. Zok-Smoły. Katowice 2016.

Film $i$ serial $w$ dydaktyce i glottodydaktyce polonistycznej. Red. W. Hajduk-Gawron, M. Wójcik-Dudek. Katowice 2016. Wydanie internetowe publikacji: http://serwer1573845.home.pl/pub/US_SEM4/index.html\#p=13

Literatura dla dzieci w kalejdoskopie sztuki. Red. G. Darłak, K. Koziołek. Katowice 2016.

Wójcik-Dudek M.: W(y)czytać Zagładę. Praktyki postpamięci w polskiej literaturze XX wieku dla dzieci i młodzieży. Katowice 2016.

„Z Teorii i Praktyki Dydaktycznej Języka Polskiego”. T. 25. Red. D. Krzyżyk. Katowice 2016.

\section{7}

Jędrych K.: Portret dziewczynki, dziewczyny i kobiety w powieściach Marii Krüger. Katowice 2017.

Koziołek K.: Czas lektury. Katowice 2017.

Literatura $w$ dydaktyce i glottodydaktyce polonistycznej. Red. W. Hajduk-Gawron, M. Wójcik-Dudek. Katowice 2017. Publikacja elektroniczna: http://serwer1573845.home.pl/pub/US_2017_SEM/\#p=5 
„Z Teorii i Praktyki Dydaktycznej Języka Polskiego”. T. 26. Red. D. Krzyżyk. Katowice 2017.

\section{8}

Język - lektura - interpretacja $w$ dydaktyce szkolnej. Red. E. Jaskółowa, M. Wójcik-Dudek. Katowice 2018.

(Od)pamiętywanie - gry z przeszłościa w literaturze dla dzieci i młodzieży. Red.

B. Niesporek-Szamburska, M. Wójcik-Dudek. Katowice 2018.

Polska pótka filmowa. Krótkometrażowe filmy aktorskie $i$ animowane w nauczaniu języka polskiego jako obcego. Red. A. Tambor, J.H. Budzik. Katowice 2018.

Przestrzenie spotkania. Tom dedykowany Profesor Ewie Jaskółowej w czterdziestolecie pracy naukowej i dydaktycznej. Red. K. Jędrych, D. Krzyżyk, M. Ochwat, M. Wójcik-Dudek. Katowice 2018.

Spoleczeństwo obywatelskie: edukacja, wartości, style komunikacyjne. Red. E. Ficek, M. Ochwat, K. Sujkowska-Sobisz, M. Wójcik-Dudek. Katowice 2018.

W krajobraz literacko-kulturowy i językowy wpisane... Księga jubileuszowa dedykowana Profesor Bernadecie Niesporek-Szamburskiej w czterdziestolecie pracy naukowej i dydaktycznej. Red. A. Guzy, D. Krzyżyk, M. Ochwat, M. Wójcik-Dudek. Katowice 2018.

„Z Teorii i Praktyki Dydaktycznej Języka Polskiego”. T. 27. Red. D. Krzyżyk. Katowice 2018.

\section{9}

Jaskóła E., Niesporek-Szamburska B., Ogłoza E., Starnawska K., Vandenborre K., Walczak-Delanois D., Wójcik-Dudek M.: Ludzie Księgi. Wokót wybranych zagadnień wydawnictwa Jakuba Mortkowicza. Katowice 2019.

„Paidia i Literatura” 2019, nr 1. Red. M. Wójcik-Dudek. Katowice.

Štěpáník S., Awramiuk E., Eliaskova K., Hajkova E., Hoflerova E., Klimovic M., Liptakova L., Niesporek-Szamburska B., Nocoń J., Szymańska M.: Vztah jazyka a komunikace v česko-slovensko-polské didaktické reflexi. Praha 2019.

Wypatrywanie. Filozoficzne aspekty języka, literaturyi edukacji. Red. M. Wójcik-Dudek, E. Zygan. Katowice 2019.

Zmysty i literatura dla dzieci i młodzieży. Red. B. Niesporek-Szamburska, M. Wójcik-Dudek. Katowice 2019. 


\section{Słowniki (wybór)}

Cząstka-Szymon B., Ludwig J., Synowiec H.: Mały stownik gwary Górnego Śląka. Wydanie drugie. Katowice 2000.

Cząstka-Szymon B., Synowiec H., Urban K.: Stownik terminów gramatycznych dla uczniów szkót podstawowych. Bielsko-Biała 1994.

Cząstka-Szymon B., Synowiec H., Urban K.: Mały słownik terminów gramatycznych. Warszawa 1996.

Dereń E., Kita M., Nowak T., Polański E.: Słownik ortograficzny w wyrażeniach. Wrocław 2005.

Dereń E., Nowak T., Polański E.: Nowy słownik języka polskiego z frazeologizmami i przystowiami. Warszawa 2005.

Dereń E., Polański E.: Szkolny słownik ortograficzny. Warszawa 2007.

Dereń E., Polański E.: Szkolny słownik ortograficzny z wierszykami. Warszawa 2013.

Kita M., Polański E.: Człowiek w krainie stów. Stownik tematyczny języka polskiego. Warszawa 2002.

Kita M., Polański E.: Stownik paronimów, czyli wyrazów mylonych. Warszawa 2004.

Nowy stownik ortograficzny PWN wraz z zasadami pisowni i interpunkcji. Red. E. Polański. Warszawa 1996.

Polański E.: Kieszonkowy słowniczek ortograficzny. Warszawa 2001.

Polański E.: Stownik ortograficzny. Katowice 1998.

Polański E.: Stownik ortograficzny. Warszawa 2002.

Polański E.: Stownik ortograficzny dla najmłodszych. Wyd. 1. Warszawa 1998. Wyd. 2. i 3. - Warszawa 1998. Wyd. 4. - Warszawa 1999.

Polański E.: Stownik pisowni łącznej i rozdzielnej. Gdańsk 2000.

Polański E., Kita M.: Stownik tematyczny języka polskiego. Łódź 2002.

Polański E., Nowak T.: Najnowszy podręcznik gramatyki języka polskiego. Kraków 2011.

Polański E., Nowak F.: Stownik ortograficzny nie tylko dla uczniów. Katowice 1995.

Polański E., Nowak F.: Słownik ortograficzny nie tylko dla uczniów. Wydanie poprawione drugie. Katowice 1996.

Polański E., Skudrzyk A.: Słownik pisowni tącznej i rozdzielnej. Razem czy osobno?. Warszawa 2003.

Polański E., Żmigrodzki P.: Leksykon ortograficzny. Warszawa 2001.

Polański E., Żmigrodzki P.: Stownik ortograficzny z zasadami pisowni i interpunkcji. Kraków 1999.

Wielki stownik ortograficzny PWN. Red. E. Polański. Warszawa 2003. 
Wielki słownik ortograficzny PWN z zasadami pisowni i interpunkcji. Red. E. Polański. Warszawa 2006.

\section{Podręczniki do kształcenia językowego i literackiego, poradniki, zbiory ćwiczeń}

Cząstka-Szymon B., Synowiec H.: Kształcenie sprawności językowej (ćwiczenia dla uczniów środowiska ślaskiego). Kraków 1990.

Cząstka-Szymon B., Synowiec H.: Polszczyzna w szkole śląskiej. Cz. 1. Katowice 1996.

Cząstka-Szymon B., Synowiec H.: Polszczyzna w szkole śląskiej. Cz. 2. Przewodnik dla nauczycieli. Katowice 1996.

Jaskóła E.: Świat do przeczytania. Kultura, język, dialogi. Język polski. Liceum i technikum kl. I. Cz. 1. Warszawa 2012 (współautorzy: K. Biedrzycki, E. Nowak).

Jaskóła E.: Świat do przeczytania. Kultura, język, dialogi. Język polski. Liceum i technikum kl. I. Cz. 2. Warszawa 2012 (współautorzy: K. Biedrzycki, E. Nowak).

Jaskóła E.: Świat do przeczytania. Kultura, język, dialogi. Język polski. Liceum i technikum kl. II. Cz. 1. Warszawa 2013 (współautorzy: K. Biedrzycki, E. Nowak).

Jaskóła E.: Świat do przeczytania. Kultura, język, dialogi. Język polski. Liceum i technikum kl. II. Cz. 2. Warszawa 2013 (współautorzy: K. Biedrzycki, E. Nowak).

Jaskóła E.: Świat do przeczytania. Kultura, język, dialogi. Język polski. Liceum i technikum kl. III. Warszawa 2014 (współautorzy: K. Biedrzycki, E. Nowak).

Krzyżyk D., Niesporek-Szamburska B., Synowiec H.: Sprawdzianyjęzykowe i ortograficzne w szkole średniej. Kielce 1995.

Krzyżyk D., Niesporek-Szamburska B., Synowiec H.: Sprawdzianyjęzykowe i ortograficzne w szkole średniej dla klasy I. Kielce 1996.

Krzyżyk D., Niesporek-Szamburska B., Synowiec H.: Sprawdziany językowe i ortograficzne w szkole średniej dla klasy II. Kielce 1996.

Krzyżyk D., Niesporek-Szamburska B., Synowiec H.: Sprawdziany językowe i ortograficzne w szkole średniej dla klasy III. Kielce 1996.

Krzyżyk D., Polański E., Starz R., Zarębska D.: Ortografia i interpunkcja w klasach IV-VIII. Wiadomości i ćwiczenia. Kielce 1994. 
Krzyżyk D., Polański E.: Testy językowe i ortograficzne dla starszych klas szkoty podstawowej (IV-VI) i gimnazjum. Warszawa 2001.

Krzyżyk D., Zeler B., Heska-Kwaśniewicz K.: „Syzyfowe prace” S. Żeromskiego. Zeszyt ćwiczeń. Katowice 1995.

Krzyżyk D., Zeler B., Heska-Kwaśniewicz K.: „W pustyni $i$ w puszczy” H. Sienkiewicza. Zeszyt ćwiczeń. Katowice 1995.

Krzyżyk D., Zeler B.: Odcień stowa. Program nauczania języka polskiego w klasach I-III liceów ogólnoksztatcacych i liceów profilowanych. Katowice 2002.

Krzyżyk D.: Dyktanda na cztery pory roku. Klasy I-III. Katowice 2003.

Krzyżyk D.: Dyktanda na cztery pory roku. Klasy IV_VI. Katowice 2003.

Krzyżyk D.: Gimnazjalista pisze dyktando. Kielce 2009.

Krzyżyk D.: Materiaty pomocnicze z zakresu dydaktyki ortografii dla nauczycieli języka polskiego na Zaolziu. Czeski Cieszyn 2006.

Krzyżyk D.: Odcień słowa. Podręcznik do kształcenia językowego dla liceów ogólnokształcacych, liceów profilowanych i techników. Klasa I. Katowice 2003.

Krzyżyk D.: Zbiór dyktand dla uczniów szkót podstawowych i średnich. Katowice 1995.

Niesporek-Szamburska B.: Bawimy się w polski 1. Klucz do zadań z komentarzem dydaktycznym. Katowice 2009 (współautor A. Achtelik).

Niesporek-Szamburska B.: Bawimy się w polski 1. Podręcznik do nauczania języka polskiego dla dzieci. Wyd. 1. Katowice 2009. Wyd. 2. — 2013. Wyd. 3. - Katowice 2014 (współautor A. A chtelik).

Niesporek-Szamburska B.: Bawimy się w polski 1. Podręcznik do nauczania języka polskiego dla dzieci. Zeszyt ćwiczeń. Wyd. 1. - Katowice 2009. Wyd. 2. — 2013. Wyd. 3. - Katowice 2014 (współautor A. Achtelik).

Niesporek-Szamburska B.: Bawimy się w polski 1. Podręcznik do nauczania języka polskiego dla dzieci. Wydanie rozszerzone. Katowice 2016 (współautor A. Achtelik).

Niesporek-Szamburska B.: Bawimy się w polski 1. Podręcznik do nauczania języka polskiego dla dzieci. Zeszyt ćwiczeń. Wydanie rozszerzone. Katowice 2016 (współautor A. A chtelik).

Orłowa K., Polański E.: Kształcenie językowe w klasach 4-8. Poradnik metodyczny. Wydanie 2. poprawione. Warszawa 1995.

Orłowa K., Synowiec H.: Jak uczyć języka polskiego w klasie drugiej gimnazjum? Poradnik dla nauczycieli. Warszawa 2000 (współautor W. Bobiński).

Orłowa K., Synowiec H.: Jak uczyć języka polskiego w klasie pierwszej gimnazjum. Przewodnik dla nauczyciela. Warszawa 2002 (współautor W. Bobiński).

Orłowa K., Synowiec H.: Język ojczysty 8. Poradnik dla nauczyciela. Warszawa 1997. 
Orłowa K., Synowiec H.: Język ojczysty. Podręcznik do kształcenia językowego dla klasy drugiej gimnazjum. Warszawa 2000.

Orłowa K., Synowiec H.: Język ojczysty. Podręcznik do ksztatcenia językowego dla klasy pierwszej gimnazjum. Warszawa 2002.

Orłowa K., Synowiec H.: Język ojczysty. Podręcznik do kształcenia językowego w klasie VIII. Warszawa 1997. Wyd. 2. - Warszawa 1998. Wyd. 3. Warszawa 1999.

Orłowa K., Synowiec H.: Język ojczysty. Podręcznik do ksztatcenia językowego w klasie trzeciej gimnazjum. Warszawa 2001.

Orłowa K., Synowiec H.: Sprawdziany dla gimnazjalistów. Warszawa 2001.

Pedagogika szkolna. Materiaty dla studentów przygotowujących się do wykonywania zawodu nauczyciela. Red. D. Krzyżyk, B. Niesporek-Szamburska przy współpracy A. Zok-Smoły. Katowice 2014.

Polański E.: Ortografia i interpunkcja w nauczaniu początkowym. Łódź 1996 (współautorzy: F. Dyka, A. Jakubowicz).

Polański E.: Ująć rzecz inaczej. Wiadomości, ćwiczenia i testy stownikowo-frazeologiczne dla szkót. Łódź 2006 (współautor M. Iw a nowicz).

Polański E.: Zabawa z ortografia. Ćwiczenia do „Stownika ortograficznego dla najmłodszych z gra planszowa »Na ratunek księżniczce»". Cz. 1. Warszawa 1998.

Polański E.: Zabawa z ortografia. Ćwiczenia do „Stownika ortograficznego dla najmtodszych z gra planszowa »Grzegorz Odważny«”. Cz. 2. Warszawa 1998.

Polański E., Orłowa K.: Ksztatcenie językowe w klasach IV—VIII. Warszawa 1994.

Polański E. przy współpracy Krzyżyk D.: Słownictwo i frazeologia w szkole. Wiadomości, ćwiczenia, testy dla gimnazjów i szkót średnich. Łódź 1999 (współautor M. Iwanowicz).

Żydek-Bednarczuk U.: Barwy epok. Nauka o języku. Podręcznik do klasy I liceum ogólnokształcacego, liceum profilowanego i technikum. Kształcenie językowe w zakresie podstawowym i rozszerzonym. Warszawa 2002 (współautor J. Kowalikowa).

Żydek-Bednarczuk U.: Barwy epok. Nauka o języku. Podręcznik do klasy II liceum. Warszawa 2003 (współautor J. Kowalikowa).

Żydek-Bednarczuk U.: Barwy epok. Nauka o języku. Podręcznik do klasy III liceum. Warszawa 2003 (współautor J. Kowalikowa).

Żydek-Bednarczuk U.: Mów i pisz po polsku. Podręcznikjęzyka polskiego dla gimnazjalistów (kl. I-III). Kraków 2001 (współautor J. Kowalikowa).

Żydek-Bednarczuk: Wspótczesna polszczyzna. Podręcznik języka polskiego dla gimnazjalistów. Kraków 1996 (współautor J. Kowalikowa). 


\section{Granty naukowe prowadzone w Katedrze}

Badania wdrożeniowe nad programem z języka polskiego $w$ klasie $V$. W: Raport z badań nad nowymi programami klasy $V$. Cz. 2. Red. A. Bogdańska-Zarembina. Wydanie IPS MOiW. Warszawa 1981, s. 1-124. Kierownik badań: Edward Polański. Wykonawcy: Jerzy Budzik, Bernadeta Niesporek, Ewa Ogłoza, Helena Synowiec, Urszula Żydek-Bednarczuk.

Badania wdrożeniowe nad programem z języka polskiego $w$ klasie VI. W: Raport z badań nad nowymi programami klasy VI. Cz. 2. Red. Anna Bogdańska-Zarembina. Wydanie IPS MOiW. Warszawa 1982, s. 10-107. Kierownik badań: Edward Polański. Wykonawcy: Jerzy Budzik, Bernadeta Niesporek, Ewa Ogłoza, Helena Synowiec, Urszula Żydek-Bednarczuk.

Badania nad jakościa w zakresie treści ksztatcenia $i$ wychowania zawartych w nowych programach wdrożonych do praktyki w szkołach podstawowych (klasy 4-8).W ramach PBP 08-17. Kierownik badań: Jerzy Jarowiecki. Kraków 1990, Cz. 1: s. 7—43, Cz. 2: s. 1—90. Koordynator: Edward Polański. Wykonawcy: Franciszek Nowak, Bernadeta Niesporek, Krystyna Orłowa, Helena Synowiec, Ewa Ogłoza, Urszula Żydek-Bednarczuk.

Projekt KBN: Odstępstwa od normy językowej (błędy językowe użytkowników języka a tendencje rozwojowe wspótczesnej polszczyzny). Nr projektu: 1H01D00413 (1997-2000). Kierownik projektu: Edward Polański. Wykonawcy: Bernadeta Niesporek-Szamburska, Krystyna Orłowa, Helena Synowiec, Urszula Żydek-Bednarczuk, Danuta Krzyżyk.

Raport na zlecenie Rady Języka Polskiego dla Sejmu i Senatu RP (2004): Język polski w szkole. Wykonawca: Helena Synowiec.

Projekt Unii Europejskiej: Slavic Network - Jezykowa i kulturowa integracja (promocja nauki języków słowiańskich metodą porównawczą — program ramowy Unii Europejskiej — Socrates Lingua 1; 2004-2007). Nr projektu: 11 3755-CP-1-2004-1-PL-LINGUA-L1. Partnerzy zagraniczni z uniwersytetów: Univerzita Palackého - Olomouc, Univerzita Komenského - Bratislava, Univerza v Ljubljani, Софийски университет „Св. Климент Охридски” София, Martin-Luther-Universität — Halle, i z radia: Българско Национално радио програма „Христо Ботев”. Kierownik projektu: Ewa Ja skółowa. Wykonawcy z Uniwersytetu Śląskiego: Bernadeta Niesporek-Szamburska, Jolanta Tambor, Romuald Cudak.

Projekt badawczy KBN: Badania nad komunikatywnościa i funkcjami podręczników do kształcenia językowego $w$ zreformowanej szkole. Nr projektu: 1H01D00726 (2004-2007). Kierownik projektu: Helena Synowiec. Wykonawcy: Danuta Krzyżyk, Bernadeta Niesporek-Szamburska, Krystyna Gąsiorek, Ewa Ogłoza, Olga Przybyla. 
Raport na zlecenie Rady Języka Polskiego dla Sejmu i Senatu RP (2007): Język podręczników szkolnych. Wykonawcy UŚ: Helena Synowiec, Danuta Krzyżyk (współautor: Krystyna Gąsiorek).

Projekt badawczy MNiSW: Wiedza o języku ojczystym we wspótczesnej szkole. Nr projektu: NN104 175636 (2009-2012). Kierownik projektu: Bernadeta Niesporek-Szamburska. Wykonawcy: Helena Synowiec, Danuta Krzyżyk, Olga Przybyla, Ewa Ogłoza, Anna Guzy, Marta Kubarek.

Raport na zlecenie Rady Języka Polskiego dla Sejmu i Senatu RP (2010): Język podręczników szkolnych do ksztatcenia zawodowego. Wykonawcy UŚ: Helena Synowiec, Danuta Krzyżyk (współautor: Krystyna Gąsiorek).

Projekt badawczy Departamentu Kształcenia Zawodowego i Ustawicznego MEN (współfinansowany z EFS w ramach Programu Operacyjnego Kapitał Ludzki): Szkoła zawodowa szkoła pozytywnego wyboru (2010-2012). Opracowanie ekspertyz językowych podręczników do przedmiotów zawodowych. Wykonawcy UŚ: Helena Synowiec, Danuta Krzyżyk.

Partnerstwo w projekcie IBE (2012-2015): Dydaktyka literatury i języka polskiego w gimnazjum w świetle nowej podstawy programowej, dotyczącym funkcjonowania w praktyce szkolnej nowej podstawy programowej kształcenia ogólnego w zakresie języka polskiego na III etapie edukacyjnym (gimnazjum) oraz tworzenia narzędzi wspierających wdrażanie podstawy programowej (znak sprawy: IBE/26/D/2012). Wartość projektu 400000 euro. Kierownik projektu: Jolanta Nocoń. Wykonawcy UŚ: Bernadeta Niesporek-Szamburska, Małgorzata Wójcik-Dudek, Anna Guzy, Karolina Jędrych, Marta Kubarek, Aleksandra Zok-Smoła.

Międzynarodowy projekt badawczy PAN i FNS-FNRS: Projekt wydawniczy Jakuba Mortkowicza (2015-2017). Kierownik UŚ: Karolina Jędrych. Wykonawcy UŚ: Ewa Jaskóła, Małgorzata Wójcik-Dudek, Ewa Ogłoza, Bernadeta Niesporek-Szamburska.

Edukacyjny grant badawczy POWR.03.01.00-00-u123/17: Będzin: kiedyś i dziś (czas realizacji 1.07.2018-31.12.2019). Kierownik projektu: Małgorzata Wójcik-Dudek. Wykonawcy: Anna Guzy, Magdalena Ochwat, Bernadeta Niesporek-Szamburska, Ewa Jaskółowa.

Grant thumaczeniowy: NPRH. Moduł „Uniwersalia 2.1” pt. W(y)czytać Zagładę. Praktyki postpamięci w polskiej literaturze XXI wieku dla dzieci i młodzieży — nr projektu 21H 170260 85. Kierownik projektu: Małgorzata Wójcik-Dudek.

Uniwersytet Polonistów realizowany od dwóch lat, obecnie (na lata 2019-2022) w ramach Uniwersytetu Humanistów na Uniwersytecie Śląskim w Katowicach. Działania 3.1. Kompetencje w Szkolnictwie Wyższym. Oś III EFS. Koordynatorzy merytoryczni: Magdalena Ochwat, Małgorzata Wójcik-Dudek. 
Grant badawczo-dydaktyczny: POWR.03.01.00-00-KN67/18: Pogranicza Edukacji Szkolnej. Program kształcenia nauczycieli języka polskiego PES. Czas realizacji 2018-11-01 do 2023-10-31. Przyznana kwota: 1131 405,72 PLN. Kierownik projektu: Ewa Jaskółowa. Wykonawcy: Małgorzata Wójcik-Dudek, Ewa Ogłoza, Bernadeta Niesporek-Szamburska, Anna Guzy, Magdalena Ochwat, Karolina Jędrych, Helena Synowiec, Danuta Krzyżyk, Olga Przybyla, Ewa Ogłoza, Dawid Matuszek.

\section{Inne osiągnięcia}

Katedra Dydaktyki Języka i Literatury Polskiej zorganizowała od lat dziewięćdziesiątych minionego stulecia 29 konferencji naukowych, w tym trzy międzynarodowe i jeden kongres dydaktyki polonistycznej.

W KDJiLP powstało wiele doktoratów. Dzięki opiece naukowej:

doc. dr Mieczysławy Mitery-Dobrowolskiej,

prof. dr. hab. Edwarda Polańskiego,

prof. dr hab. Anny Opackiej,

prof. dr hab. Heleny Synowiec,

prof. dr hab. Urszuli Żydek-Bednarczuk,

prof. dr. hab. Bogdana Zelera,

prof. dr hab. Ewy Jaskółowej,

prof. dr hab. Bernadety Niesporek-Szamburskiej

- świętowano 65 promocji doktorskich.

Przy Katedrze działały dwa studenckie koła naukowe: od dziesięciu lat pod opieką dr Anny Guzy prężnie działa Studenckie Koło Naukowe „Bakałarz” — członkowie organizują ogólnopolskie konferencje naukowe, uczestniczą w badaniach naukowych i publikacjach.

Zestawienie przygotowały Anna Guzy, Bernadeta Niesporek-Szamburska i Helena Synowiec 